\title{
Five Challenges of Designing Disability Income Support for People with Mental Illnesses: A Qualitative Case Study of Australia and Ontario
}

\author{
Ashley McAllister \\ Karolinska Institutet
}

\begin{abstract}
In most disability income support (DIS) programs, mental illnesses is the fastest growing category of illness, but it is unknown how policy designers consider this vulnerable group. Forty-five DIS policy designers in Australia and Ontario explained how they consider mental illnesses when designing policy. Using a grounded theory approach, five challenges emerged: validating duration, proving an illness, (un)differentiating mental illnesses, managing mental illnesses, and separating the person from the illness. Each challenge is described and compared across Australia and Ontario. These challenges provide a framework for other settings to determine how well their DIS policies have considered mental illnesses in policy design.
\end{abstract}

Keywords: Australia, Ontario, mental illness, disability income support, grounded theory.

\section{RÉSUMÉ}

Dans la plupart des programmes de soutien du revenu en cas d'invalidité, les maladies mentales sont la catégorie de maladies qui connaît la croissance la plus rapide; or, on ne sait pas exactement comment les concepteurs de politiques considèrent ou évaluent ces maladies et les personnes qui en souffrent, qui constituent un groupe vulnérable. Dans ce rapport, 45 concepteurs de politiques travaillant en Australie et en Ontario expliquent leur vision de la maladie mentale. Grâce à ces témoignages, et à l'aide d'une méthodologie de théorie à base empirique, j'ai relevé cinq défis qui se posent: la validation de la durée, la preuve

Ashley McAllister, Menzies Centre for Health Policy, University of Sydney, Sydney, Australia.

Ashley McAllister is now at the Department of Public Health Sciences, Karolinska Institutet, Stockholm, Sweden.

During the completion of this work, Ashley McAllister was a recipient of a Canadian Institute of Health Research Foreign Doctoral Research Award (Ref No. 291189). This funding body had no role in the conduct or reporting of the study.

Correspondence concerning this article should be addressed to Ashley McAllister, Department of Public Health Sciences, Solnavägen 1, 17177 Solna, Sweden. Email: ashley.mcallister@ki.se 
d'une maladie, la difficulté de différencier certaines maladies mentales, la gestion des maladies mentales et la séparation de la maladie de l'individu qui en souffre. Je décris chacun de ces défis et je compare la façon dont il se pose et est traité en Australie et en Ontario. L'ensemble forme un cadre qui pourrait être utilisé ailleurs pour permettre d'évaluer la façon dont la maladie mentale est traitée dans la conception de programmes de soutien du revenu en cas d'invalidité.

Mots clés : Australie, Ontario, maladie mentale, soutien du revenu en cas d'invalidité, méthodologie de théorie à base empirique.

Recovery from mental illnesses is not possible without access to certain fundamental supports such as income (Mental Health Commission of Canada, 2012). For some people, such support can be more important than "formal mental health services" (Trainor, Pomeroy, \& Pape, 2004). Indeed, this is a theme that runs through the Canadian Mental Health Strategy (MHCC, 2012). Governments provide disability income support payments to those unable to generate their own income because of their disability. But how do policy-makers determine who can and cannot work because of their mental illness? Clear answers are not found in the academic literature.

Disability income support payments are not universal. Boundaries are drawn between who can and cannot receive this government support (Stone, 1984). However, little analysis exists about how this line is drawn and, more importantly, how certain types of disabilities such as mental illnesses are considered when drawing this line. This article addresses this gap to understand how policy-makers design the eligibility and assessment process for disability income support and how mental illnesses are recognized in this process. As such, this paper builds on another theme of the Strategy, that mental health is a concern of all of governments not just the health sector by focusing on how policy-makers in social services consider mental illnesses.

\section{OVERVIEW OF DISABILITY INCOME SUPPORT AND RATIONALE FOR SELECTION OF CASE STUDIES}

While there are similarities, each disability income support payment has its own detailed rules and differing payment rates and is influenced by contextual factors. In recognition of this, the Australian Disability Support Pension (DSP) and the Ontario Disability Support Program (ODSP) were chosen as the focus of this study. The following section outlines the rationale for selecting these settings.

In terms of policy learning (Dolowitz \& Marsh, 2000), Australia and Canada are natural comparisons. Both have inherited political traditions from Britain and remain Commonwealth countries; they have federal systems of government; geographically they are vast countries with urban centres but many regional and rural areas. In addition, both are liberal welfare states with universal health insurance. Such similarities could explain why they have been compared in other health studies (see for example Deber, 2005; Hurley, Vaithianathan, Crossley, \& Cobb-Clark, 2002; Moulding et al., 2009; Tempier et al., 2009). In fact, Australia's Medicare system was largely inspired by Canada's universal health system (Dunlop, 1983). However, in Canada, provinces are responsible for providing last resort disability income support payments such as the ODSP. Recognizing that an entire study could be dedicated to comparing the provincial systems, this study 
is limited to the province of Ontario. Ontario is Canada's most populous province, and the ODSP is one of the few programs (including internationally) that explicitly excluded drug and alcohol dependence from its initial design of the program (the exclusion provision has since been repealed; Hales-Ricalis, 2010) making it an interesting policy case study for how mental illnesses are considered. Furthermore, at the time of this study, the Ontario government was considering a major overhaul of the ODSP (Lankin \& Sheikh, 2012). Part of this consideration was whether to adopt the Australian DSP approach. The Australian DSP has been lauded by the Organisation for Economic Co-operation and Development (OECD) for their work capacity approach and specifically incorporating the fluctuating nature of mental illnesses into the DSP assessment process (OECD, 2012) making it a "best practice" case in disability income support research. Despite OECD's accolades, limited academic research exists about how DSP policy-makers have considered mental illnesses. I wanted to understand in greater depth why Ontario might follow in Australia's footsteps.

\section{Overview of the Contexts}

Table 1 on the next page provides a descriptive summary of the central elements of the Australian DSP and the Ontarian ODSP.

Table 1 illustrates that the DSP is more generous than the ODSP. However, the DSP has much tighter eligibility requirements. Overall, the DSP design is more prescriptive, such as specifically listing eligible conditions, whereas ODSP has more discretion about what conditions might be eligible. An exception is that ODSP initially excluded alcohol and drug dependence until case law overturned this policy decision. McAllister, Hackett, and Leeder (2017) conducted a literature review finding limited results in both settings. What does exist is not comparative in nature (see for example Carney, 1991; Hales-Ricalis, 2010; Madden, Glozier, Mpofu, \& Llewellyn, 2011; Mendelson, 2004) except for one article (Brucker, 2009).

The aim of this study is to contribute knowledge on how disability income support policy is designed, especially regarding mental illnesses, based on data from those who designed the policies. More specifically, the following research questions are addressed: (1) What challenges (if any) do mental illnesses present when designing disability income support design? and (2) How do these challenges compare across Australia and Ontario?

\section{METHODS}

A constructivist grounded theory approach (Charmaz, 2006) was used to learn about how those who design disability income support policy consider mental illnesses. Because mental illnesses is an umbrella term used to describe many different types of illnesses, three mental disorders - drug and alcohol dependence (hereto referred to as addiction), depression (unipolar), and schizophrenia - have been selected for use when more specific analysis of policy design is needed. They represent conditions that contribute most to the burden of disease attributable to mental illnesses (Prince et al., 2007).

\section{Sampling and Recruitment}


Table 1

Overview of the DSP and ODSP

\begin{tabular}{|c|c|c|}
\hline & Australia & Ontario \\
\hline Program name & Disability Support Pension & Ontario Disability Support Program \\
\hline Administered by & Department of Social Services (Federal) & $\begin{array}{l}\text { Ministry of Community and Social } \\
\text { Services (Provincial) }\end{array}$ \\
\hline Size of program & $3.5 \%$ of total Australian population ${ }^{1}$ & $3.4 \%$ of total Ontarian population ${ }^{5}$ \\
\hline $\begin{array}{l}\% \text { of recipients with } \\
\text { mental illnesses }\end{array}$ & $31 \%^{1}$ & $38 \%{ }^{6}$ \\
\hline $\begin{array}{l}\text { Basic definition of dis- } \\
\text { ability }\end{array}$ & $\begin{array}{l}\text { Not able to work more than } 15 \text { hours in the next } \\
\text { two years ( } 8 \text { hours for those under } 35 \text { years of } \\
\text { age) as a result of a severe (see note) impair- } \\
\text { ment. } \\
\text { Note: Severe is interpreted as } 20 \text { points under } \\
\text { the Impairments Tables. The Tables list eligible } \\
\text { conditions and provide impairment ratings. }\end{array}$ & $\begin{array}{l}\text { Must have a substantial restriction } \\
\text { in the person's ability to work, take } \\
\text { care of him or herself or take part in } \\
\text { the community that is expected to last } \\
\text { more than one year.? }\end{array}$ \\
\hline $\begin{array}{l}\text { Disability assessment } \\
\text { process }\end{array}$ & $\begin{array}{l}\text { The Job Capacity Assessment is completed } \\
\text { face-to-face with a DSP assessor. }\end{array}$ & $\begin{array}{l}\text { The Disability Determination Pack- } \\
\text { age is completed by the applicant, and } \\
\text { then the Disability Adjudication Unit } \\
\text { assesses the paper application. }{ }^{8}\end{array}$ \\
\hline Governing legislation & Social Security Act, $1991^{2}$ & $\begin{array}{l}\text { The Ontario Disability Support Pro- } \\
\text { gram Act, } 19977\end{array}$ \\
\hline $\begin{array}{l}\text { Annual payment for a } \\
\text { single person }\end{array}$ & \$CAD $19,837^{4}$ & $\$ C A D 13,320^{9}$ \\
\hline
\end{tabular}

Note: Benefit rates as at 30 May 2016. Amounts are annual and in Canadian dollars (Bank of Canada 2015).

${ }^{1}(\text { DSS, 2013 })^{2}\left(\right.$ DSS, 1991) ${ }^{3}\left(\right.$ Australian Government, 2015) ${ }^{4}\left(\right.$ DHS, 2016a) ${ }^{5}(\text { MCSS, 2016a })^{6}($ MCSS, 2011)

${ }^{7}(\mathrm{MCSS}, 1997){ }^{8}(\mathrm{MCSS} 2012){ }^{9}($ Income Security Advocacy Centre, 2015)

Source: Author's compilation.

In this study, all informants are or were involved in designing disability income support in Australia or Ontario. Initial informants were identified through Senate Estimate Committee Hearings (Australian Government, 2013), government organizational charts, government submissions, literature, and informal discussions. Subsequent informants were identified through snowball sampling (Tansey, 2007). To ensure that recommendations were not limited to an informant's network, multiple chains were started (Penrod, Preston, Cain, \& Starks, 2003). Most informants were recommended more than once. Once focused codes (see data analysis section for definition) were established, theoretical sampling was used. Theoretical sampling involves selecting informants (or documents) to elucidate information that further explains conceptual categories rather than producing representative findings (Birks \& Mills, 2010; Bryant \& Charmaz, 2007). Informants towards the end of data collection were chosen to help elaborate and refine major categories (Charmaz, 2006). In total, 45 informants were interviewed from March 2012 to September 2013. Table 2 provides a summary of informant characteristics. 
Table 2

Informant Characteristics

\begin{tabular}{lll}
\hline Demographic & $\mathrm{N}=45$ & $\%$ \\
\hline Location & & \\
Australia & 20 & $44 \%$ \\
Ontario & 25 & $56 \%$ \\
Age & 2 & \\
$25-34$ & 5 & $4 \%$ \\
$35-44$ & 13 & $29 \%$ \\
$45-54$ & 18 & $40 \%$ \\
55 and older & 7 & $16 \%$ \\
No answer provided & & \\
Primary Discipline & 5 & $11 \%$ \\
Economics & 5 & $11 \%$ \\
Law & 9 & $20 \%$ \\
Medicine & 8 & $18 \%$ \\
Mental health & 1 & $2 \%$ \\
Occupational therapy & 2 & $4 \%$ \\
Public policy & 13 & $29 \%$ \\
Social policy & 2 & $4 \%$ \\
No answer provided & & \\
\hline
\end{tabular}

Source: Author's compilation.

A similar number of informants were interviewed in both settings. Most informants were older than 55 years, had several years of experience designing disability income support policies, and held senior positions (i.e., managers, directors, ministers). Table 2 shows that the informants came from a variety of different disciplines ranging from medicine to public policy.

Policy documents (i.e., legislation, program guidelines) were identified through a systematic literature review (McAllister et al., 2017) and informant interviews. These documents were used to triangulate data from interviews.

\section{Data Collection}

Most interviews were conducted face-to-face lasting between 25 and 120 minutes. Some interviews were conducted via Skype for logistical reasons. The author conducted all interviews. Informants were asked 
to describe their role in designing disability income support and any challenges in this process related to mental illnesses. Interviews were digitally recorded and transcribed verbatim. After analysis, ellipsis (...) was used to remove repetitive text (e.g., ums and ahs) but not to alter the meaning of a quote. To differentiate between informants in Australia and Ontario, (A) denotes an Australian informant and (O) denotes an Ontarian informant.

\section{Ethics}

The study was approved by the Human Research Ethics Committee at The University of Sydney. Prior to commencing interviews, informants were provided with a study information sheet and provided written consent. Participation in the study was voluntary.

\section{Data Analysis}

Data analysis followed the central tenets of constructivist grounded theory (Sbaraini, Carter, Evans, \& Blinkhorn, 2011) including detailed memo writing, constant comparison, coding, and diagramming. The categories presented in this article were derived from initial and focused codes. Initial coding entailed coding the first six transcripts line-by-line as a way to "break open the data" (Corbin \& Strauss, 2008) and remove the researcher's preconceptions. An additional four transcripts were coded line-by-line halfway through data collection to identify any additional codes. Initial codes, memos, and detailed field notes were triangulated to develop focused codes. Focused codes can include codes that repeated or that the author perceived as significant. Focused codes were explored in subsequent interviews until theoretical saturation occurred at 42 interviews. The author conducted an additional three interviews ensuring that all codes had been suitably developed. Diagramming was used to see how focused codes interconnected. From this analysis, the core category of understanding mental illnesses that encompassed five sub-categories was created. These subcategories are validating duration, proving an illness, (un)differentiating mental illnesses, managing mental illnesses, and separating the illness from the person.

The author conducted the analysis with the guidance of an advisory team including having fortnightly meetings and discussing data collection and preliminary results. Results were periodically presented at seminars and conferences to increase the credibility and dependability of results.

\section{FINDINGS}

Five challenges related to designing disability income support and mental illnesses emerged: validating duration, proving an illness, (un)differentiating mental illnesses, managing mental illnesses, and separating the illness from the person. In the following section, each challenge is explored, and the informants' perceptions are presented. Many of the categories overlap and overall are about understanding mental illnesses.

\section{Validating Duration}

In both settings, a central eligibility criterion is determining the duration of a disability. The DSP policy requires a disability last at least two years, and the ODSP policy requires a disability last at least a 
year. Many informants said this criterion is challenging when it comes to applicants with mental illnesses. For example, Informant 42 (A) said:

It really is just such a difficult issue to deal with, particularly if people at Centrelink or [Department of] Human Services are having to make judgments around someone's ability to work, which on one day there might be no chance in the world of turning up to work, yet another day they might be fine.

Although the DSP and the ODSP legal definitions include specific wording to include episodic conditions (DSS, 1991; MCSS, 1997), Informant 42 (A) perceived the interpretation of this component to be challenging when it came to applicants with mental illnesses. When asked if any policy tools were developed to help interpret this criterion for applicants with mental illnesses, none was provided.

Informant $23(\mathrm{O})$ said ODSP policy design is binary- "You're in or you're out. You either have this condition, or you don't." Such an approach makes it challenging to accommodate non-binary conditions such as many mental illnesses.

\section{Proving an Illness}

Another crucial eligibility criterion is providing proof that an applicant's disability impairs their ability to function. However, Informant 36 (A) said that unlike many physical illnesses, mental illnesses do not have tests (e.g., blood tests, $\mathrm{x}$-rays) proving a person even has the illness.

Well, we [psychiatrists] don't have tests like they do in the general hospital, in the same way, blood tests for many things... for schizophrenia, there's no sort of reliable test. I suppose you have rating scales, but there's no objective gold standard like there is in many physical conditions in general medicine.

As a result, disability income support decision-makers rely on testimony from physicians and applicants rather than diagnostic test results. For applicants with severe mental illnesses this did not seem to be a problem because as Informant 30 (A) said:

At the more severe end, there are disability measures that are reasonably objective, and repeatable and measurable. So things like days out of role [e.g., how many days a person was unable to work or carry out normal activities as a result of their mental illness] and days spent in [hospital] bed.

Proof of more moderate mental illnesses is more challenging. Informant $28(\mathrm{O})$ said that ODSP is not designed to capture those with several moderate symptoms, which cumulatively make work impossible.

...what they're [ODSP adjudicators] really looking for is almost a killer blow to your ability to do anything. So incredibly severe symptoms that stop you leaving the house, but if you have moderate symptoms which altogether mean that it's just never going to work, the scoring makes that difficult. For example, ODSP forms ask about emergency room visits or hospital admissions that may not be applicable to those with more moderate symptoms.

\section{(Un)differentiating Mental Illnesses}

Mental illnesses were spoken about as an umbrella category. In general, most informants (except for those with a medical background) spoke about mental illnesses in a general sense rather than specifically addressing different types of mental illnesses. The Australian Impairment Tables - a central tool used to assess DSP eligibility_also reflects this generalization of mental illnesses. Of 15 tables, only two (Table 5: 
Mental health function and Table 6: Functioning related to alcohol, drug, and other substance abuse) relate to mental health conditions (DSS, 2012). In Ontario, the Disability Adjudication Framework provides guidance on how different types of mental illnesses are addressed (i.e., there is separate information for how to assess mood disorders, psychotic disorders, eating disorders, etc.).

An exception was addiction. Many informants differentiated addiction from other types of mental illnesses. For example, Informant 20 (O) said: "I don't want to say the true rate of mental health conditions... because that divide is so fuzzy, between an addiction being part of a mental health issue, I usually pull that number out."

When prompted to speak about specific illnesses, schizophrenia was often spoken about as a severe mental illness and depression or anxiety as a less severe mental illness. For example, Informant $14(\mathrm{O})$ said:

Let's not talk about the schizophrenic [sic] one but let's talk about the larger group of depression and anxiety... who were maybe working and were having a hard time in [sic] employment situation, became unemployed $[\mathrm{sic}]$ their pathology got worse because they are poor, and our income support levels are very low in Ontario.

Informant $44(\mathrm{O})$ thought a hierarchy existed with physical illnesses at the top, followed by mental illnesses and then addiction because the public perceives that people are at fault for their addiction.

\section{Managing Mental Illnesses}

Informants also spoke about some assumptions related to the medical management of mental illnesses. Informant 35 (A) said they assume that "...someone who is so severely impaired that they cannot work would get some kind of specialist support, and or specialist diagnosis, or specialist treatment, so that they had the greatest chance of living at their capacity."

To them, seeing a specialist is a marker of severity of impairment. Most informants said that a specialist (e.g., psychiatrist or psychologist) report is preferred over a general practitioner (GP) report, especially for applicants with mental illnesses. In Australia, the Department of Human Services specifies that an applicant with a mental health condition must have been diagnosed by a psychologist or psychiatrist (DHS, 2016b). However, in Ontario, GPs and registered nurses can provide evidence in addition to specialists (MCSS, 2012). Informants were divided on the issue of management of mental illnesses. While some informants echoed Informant 35 (A)'s sentiments, others spoke about issues of access. Informant 44 (A) said, "It is very hard to get mental health services, particularly access to a psychiatrist, unless you are acutely suicidal or acutely psychotic or unless you have money."

Informant 38 (A) said that many people with mental illnesses do not seek care at all, especially in rural settings or Indigenous communities, due to the stigma attached to mental illnesses.

\section{Separating the Illness from the Person}

Most informants discussed the relationship between social factors and a person's disability. The DSP and ODSP legislation explicitly exclude most social factors related to an applicant's situation, such as education and labour market availability (DSS, 1991; MCSS, 1997). However, ODSP case law (Gray vs. Director) ruled that age, gender, and work history must be considered (Gray v. Director of the Ontario Disability Support 
Program, 2002). According to Informant 34 (A), the policy rationale for excluding non-medical factors is that "... social factors should be able to be addressed. So it shouldn't be a disadvantage, we should be able to do something about social factors."

This was a polarizing issue among the informants. Many informants iterated similar statements to Informant 34 (A) perceiving these factors as irrelevant for assessing disability income support. On the other hand, Informant 17 (O) thought it was "ludicrous" to ignore the relationship between social factors and a person's mental illness. He gave an example:

If I had a movie star with a very significant addiction, they may be disabled, but they have so many means around them that if I can help them channel them, they may not need to get assistance from the state to manage those things. Whereas somebody else who has lost everything, doesn't have anything, will need the state's assistance to make sure there's a roof over their head.

Informant 5 (A) said once a person with addiction gets to the point of needing disability income support, it is a "fantasy" to believe that much will change. Informant 30 (A) described the domino effect, including homelessness, that having a mental illness can have on a person.

You haven't got a mailing address, it's harder to get the access to information, if you were able to work you can't field job offers, you're much more likely to get a physical health problem, you're more likely to get into financial problems, you're more likely to get into forensic justice problems because of stealing, gambling, whatever, and you're much more likely to get into either assaulting people or being assaulted.

\section{DISCUSSION}

The aim of this study was to contribute knowledge on how mental illnesses are considered when designing disability income support policy in Australia and Ontario. Despite differences in design illustrated in Table 1, results showed little variation across settings. Table 3 on the next page summarizes how the DSP and the ODSP address each of the five challenges introduced in this paper.

Results contradict the OECD praise for the Australian DSP policy incorporating fluctuating conditions in the assessment (OECD, 2012). While Australian and Ontarian disability income support legislation includes terminology such as episodic and fluctuating, the challenge is interpreting it in practice. Tools need to be designed to assist with interpretation and implementation. Other studies also recognize this challenge when designing disability income support policy in Australia and Ontario (Carney, 1991; Lightman, Vick, Herd, \& Mitchell, 2009; Madden et al., 2011).

Results suggest that disability income support policy does not reflect the fragmentation and shortage of mental health and addiction services available in Australia and Ontario (Bartram \& Chodos, 2013; Judd \& Humphreys, 2001; Mulvale \& Bourgeault, 2007; O'Reilly et al., 2007), or that there is a high rate of people with mental illnesses not accessing treatment (Currie, Fiest, \& Guyn, 2013; Kohn, Saxena, Levav, \& Saraceno, 2004; Whiteford et al., 2014). Preferring psychiatrists' or psychologists' care to other types of healthcare professionals also demonstrates a lack of recognition of the trend towards collaborative care for people with mental illnesses (Prince et al., 2007).

Substantial evidence in the literature supports the interconnectedness of the social determinants of health and impairment related to mental illnesses (see for example Fryers, Melzer, \& Jenkins, 2003; Fryers, Melzer, 
Table 3

\section{Comparing How the DSP and ODSP Address the Five Challenges}

\begin{tabular}{|c|c|c|}
\hline Challenge & DSP & ODSP \\
\hline \multirow[t]{2}{*}{ Validating duration } & $\begin{array}{l}\text { Definition includes "episodic and fluctuat- } \\
\text { ing" recognizing conditions such as mental } \\
\text { illnesses }\end{array}$ & $\begin{array}{l}\text { Definition includes "recurrent" recognizing } \\
\text { conditions such as mental illnesses. }\end{array}$ \\
\hline & $\begin{array}{l}\text { Unclear how this wording is interpreted in } \\
\text { practice. }\end{array}$ & $\begin{array}{l}\text { Unclear how this wording is interpreted in } \\
\text { practice. }\end{array}$ \\
\hline $\begin{array}{l}\text { Proving a mental } \\
\text { illness }\end{array}$ & $\begin{array}{l}\text { An applicant proves their mental illness in } \\
\text { two ways: } \\
\text { written evidence from a psychiatrist or } \\
\text { psychologist; and } \\
\text { verbal self-testimony in a face-to-face as- } \\
\text { sessment. }\end{array}$ & $\begin{array}{l}\text { An applicant proves their mental illness by } \\
\text { providing written evidence from a GP, psy- } \\
\text { chiatrist, or psychologist. } \\
\text { Note: An applicant can also complete an } \\
\text { optional self-assessment form. }\end{array}$ \\
\hline \multirow[t]{2}{*}{$\begin{array}{l}\text { (Un)differentiating } \\
\text { mental illness }\end{array}$} & $\begin{array}{l}\text { Limited differentiation as all types of men- } \\
\text { tal illnesses are assessed using Impairment } \\
\text { Table 5-Mental Health Function with } \\
\text { the exception addiction, which is assessed } \\
\text { under Table 6-Addiction. }\end{array}$ & $\begin{array}{l}\text { Some differentiation as the Disability Adjudi- } \\
\text { cation Framework provides separate guidance } \\
\text { on how to assess different types of mental } \\
\text { illnesses. }\end{array}$ \\
\hline & & $\begin{array}{l}\text { Initially, addictions were considered separate } \\
\text { from other types of mental illnesses. }\end{array}$ \\
\hline \multirow[t]{2}{*}{$\begin{array}{l}\text { Managing mental } \\
\text { illnesses }\end{array}$} & $\begin{array}{l}\text { DSP policy expects applicant to have been } \\
\text { diagnosed by a psychiatrist or psychologist. }\end{array}$ & $\begin{array}{l}\text { ODSP written policy recognises that people } \\
\text { with mental illness see a wide range of health } \\
\text { professionals. }\end{array}$ \\
\hline & & $\begin{array}{l}\text { In practice, evidence is preferred from a psy- } \\
\text { chologist or psychiatrist. }\end{array}$ \\
\hline $\begin{array}{l}\text { Separating the } \\
\text { person from the } \\
\text { illness }\end{array}$ & DSP policy excludes non-medical factors. & $\begin{array}{l}\text { ODSP legal definition excludes non-medical } \\
\text { factors, but due to case law age, education, } \\
\text { and work history must be considered. }\end{array}$ \\
\hline
\end{tabular}

Source: Author's compilation. 
Jenkins, \& Brugha, 2005; Heim \& Nemeroff, 2001; Kessler \& Foster, 1995; Kieling et al., 2011; McGorry \& Goldstone, 2011; Mulvale \& Bartram, 2015; Muntaner, Eaton, Miech, \& O'Campo, 2004; Walker et al., 2011). Despite this evidence, these factors are explicitly excluded in definitions of disability in both settings.

The greatest variation between both settings was Challenge 5: Separating the person from the illness. In Ontario, some social factors such as age and work history must be considered when assessing ODSP eligibility whereas these are excluded in the Australian assessment. However, this inclusion is a result of the strong human rights framework in Ontario. The Tranchemontagne case (Copes \& Bisgould, 2010) illustrates the importance the legal framework in Ontario. In this landmark case, the appellants were rejected from the ODSP because addictions were not an eligible condition. However, the case went through many levels of the appeal process, and ultimately the Supreme Court of Canada ruled that excluding people with addiction was discriminatory and ODSP policy was forced to change. As a result of this decision (and not intentional policy design), addiction is now an eligible condition in ODSP policy.

Despite acclaim from the OECD, Table 3 indicates that the Australian DSP is not better at incorporating mental illnesses into their policy design compared to the ODSP. In fact, the ODSP seems to incorporate the challenges slightly better than Australia. However, overall, both settings address each challenge in some way, but neither is an exemplar for how to consider mental illnesses in disability income support policy design. A limitation of this study is that it is unknown if this is intentional or due to a lack of resources.

The results present an opportunity for the mental health community to collaborate with the relevant government department in each setting (e.g., the Ontario Ministry of Community and Social Services). Table 3 provides a starting point for where improvements are needed and collaboration could be useful.

Table 4 summarizes the five policy challenges discussed in this paper. The challenges include both features and assumptions about mental illnesses.

Overall the challenges of mental illnesses in policy design are a neglected area of the literature. However, some practical examples of how to move forward exist. For example, the Swedish Social Insurance Agency

\section{Table 4}

\section{Five Disability Income Support Policy Challenges Related to Mental Illnesses}

Validating duration: the fluctuating and episodic nature of many mental illnesses makes predictions about duration difficult.

Proving an illness: no definitive diagnosis and invisibility of symptoms makes proving a person has a mental illness difficult.

(Un)differentiating mental illnesses: while many mental illnesses share broad characteristics, each has unique features including symptoms, forms of treatment and impairments.

Managing mental illnesses: high rates of people with mental illnesses are not accessing treatment.

Separating the person from the illness: difficult to delink a person's mental illness from their circumstance.

Source: Author's compilation. 
(Försäkringskassan) and the Karolinska Institutet, Sweden's largest medical school, provide training to medical students and current doctors on how to address invisible illnesses and conduct medical assessments related to disability income support (Karolinska Institutet, 2017). That said, even in Sweden, disability income support policy design trends exclude non-medical factors from eligibility criteria as well as preferring assessments by mental health specialists rather than GPs.

However, there are a few promising options for policy learning. First, the Danish system employs assessment teams that include government staff, physicians, and social workers providing a more holistic assessment (Baumberg, Warren, Garthwaite, \& Bambra, 2015) and hopefully leading to better inclusion of the challenges of mental illnesses outlined in this paper. However, a case study on the Danish system applying the five challenges is needed. Second, a collaborative research team at the National Institutes of Health and Boston University have developed the Work Disability Functional Assessment Battery (WDFAB; Meterko et al., 2015). The WD-FAB covers eight domains of whole person functioning and uses item response theory and computer adaptive testing. The sophisticated yet flexible nature of this tool means that some bias related to physician or disability adjudicators could be eliminated while incorporating specific challenges related to mental illnesses.

\section{What's New?}

Since the completion of this study, both settings have policy updates. First, the Ontario Government decided against overhauling their social assistance system but did commit to increasing the rate of ODSP payment (MCSS, 2013). In 2016, the Ontario Ministry of Community and Social Services committed to simplifying the system including improving the ODSP adjudication process and medical reviews (MCSS, 2016b). These changes arose from significant lobbying by those with mental illnesses, advocates, and stakeholders. Canadian Mental Health Association CEO, Camille Quenneville, noted that the changes to the medical reviews in particular would have an impact on those with mental illnesses (Canadian Mental Health Association: Ontario, 2016). However specific details on how and why this is the case are limited.

In Australia, an interim report was released in June 2014 reviewing Australia's welfare system. It recommended that the eligibility criteria for the DSP should be narrowed to only "people with a permanent impairment and no capacity to work" (DSS, 2014). In response to the report, the Mental Health Council of Australia (MHCA) and the National Mental Health Consumer and Carer Forum (NMHCCF) noted concern about how this would be applied in practice and that this could put those with mental illnesses at a disadvantage when applying (MHCA \& NMHCCF, 2014). In December 2014, it was announced that GPs would be banned from completing DSP forms (Andrews, 2014) and Commonwealth-appointed doctors (who would not be familiar with the person and their mental illness) would now be responsible for making the assessment. Overall these updates demonstrate that the challenges identified in this paper still need to be addressed.

\section{Strengths}

To the best of my knowledge, no other study summarizes the main policy challenges related to disability income support design and mental illnesses in these settings. In addition, the results contribute to the 
literature by creating a framework for policy-makers and researchers to use when designing and evaluating disability income support design in relation to mental illnesses.

Another strength of this study is that few articles on this topic in these settings (McAllister et al., 2017) use data generated from those who were involved in designing these benefits.

\section{Limitations}

A major limitation of qualitative research is that samples are subject to potential bias because informants are selected to produce rich data, not to be representative (Malterud, 2001). In this article, informants were selected based on their experiences in disability income support policy design. Findings are limited to the perspectives of those who participated and may not reflect those who did not participate. Obviously, this limits the generalizability of the findings.

Another limitation is that this article focused on mental illnesses. Although it was outside the scope of this article, I acknowledge that many physical illnesses, like chronic back pain and chronic fatigue syndrome, may present similar challenges to disability income support policy-makers. Finally, I acknowledge that many people with mental illnesses also have co-occurring physical illnesses; however, this study did not specifically address the policy challenges related to such situations.

\section{CONCLUSION}

Although findings from this study are limited to Australia and Ontario, the five challenges are not context specific. For example, all disability income support designers must deal with the challenge of fluctuating conditions and choosing whether to include or exclude social factors in eligibility criteria. Future research should focus on determining how other jurisdictions face these challenges to see if there are any opportunities for policy learning.

Furthermore, despite the large number of disability income support recipients with mental illnesses in both places (MCSS, 2011; DSS, 2013), there still seems to be a fundamental lack of understanding and more importantly acceptance of some aspects related to mental illnesses especially in regard to management of mental illnesses and social determinants of health. A greater understanding is imperative since lack of adequate consideration of mental illnesses in disability income support policy design can have dire consequences (Trainor et al., 2004). As seen in the UK, neglect in disability income support policy design resulted in increased suicide rates (Barr et al., 2015). Future research should determine if the challenges highlighted in this paper are intentionally ignored or if there are inadequate resources available to deal with these challenges.

\section{How the Five Challenges Relate to the Canadian Mental Health Strategy}

In the Canadian Mental Health Strategy, there are 15 references to income and 17 to poverty. In fact, Priority 3.5 specifically focuses on increasing access to income among other supports and Priority 4.1 focuses on social determinants of health including a discussion on poverty. In Canada, income is needed to afford many prescriptions. Income is imperative to securing housing. Income can also help families afford 
recreational activities (e.g., swimming lessons) increasing their physical activity. However, some people with mental illnesses are unable to secure income through employment, and that is where disability income support benefits play a role. Indeed, recommendation 3.5.4 is "Make disability benefit programs more adaptable to the individual needs of people living with mental health problems and illnesses..." (MCHA, 2012, p. 56). Priority 3.5 (MCHA, 2012, p. 53) highlights the Strategy's emphasis on incorporating mental health into all policies, not just health policies. This paper provides an extension of recommendation 3.5.4 in that consideration of the five challenges presented in this paper by policy-makers responsible for disability benefit programs could lead to benefits that are more adaptable to those with mental illnesses.

The Canadian Mental Health Strategy explicitly acknowledges that mental health is the concern of many government departments, such as social services, education, and finance and not just the health department (MHCA, 2012, p. 9). The challenges presented in this paper provide a simple framework for non-health sectors and what factors should be considered when considering mental health in all policies.

\section{The National Disability Insurance Scheme and Mental Illnesses}

Since the completion of this study, the Australian Government gradually introduced the National Disability Insurance Scheme (NDIS) across Australia. The following is a postscript providing some details about the NDIS and how the five challenges outlined in this paper relate to the NDIS.

The NDIS will provide approximately 460,000 Australians under the age of 65 who are born with or acquire a disability with no-fault insurance coverage (i.e., lifetime costs of disability-related care; Malbon, Carey, \& Dickinson, 2017). The NDIS is a unified national scheme meant to provide more comprehensive and personalized support than the previously fragmented disability care and support system in Australia. The insurance approach focuses on individuals and their lifetime costs rather than the disability welfare approach where services and programs are tied more to political motives and balancing the budget. And unlike the Disability Support Pension, it is not means tested.

However, the NDIS is not a magic bullet to solve inequality issues related to disability income support especially when it comes to mental illnesses. According to Mental Health Australia [MHA] (2017) “... the NDIS will provide more public funding to address psychosocial disability, but for a smaller number of people." It is important to note that the NDIS was not designed to replace the Australian mental health system or any care for those with mental illnesses. In fact, mental health support was a "last minute" addition to NDIS program (Morton, 2017). Critics purport that the NDIS was designed more for people with physical and intellectual disabilities than mental illnesses which means that the program has overlooked some of the challenges presented in my paper. An example is the NDIS eligibility requirement that a disability must be permanent. Patrick McGorry, a leading mental health expert in Australia, said overlooking the fluctuating nature of mental illnesses means that the NDIS model does not fit with mental illnesses (Morton, 2017). As I argued in my paper, disregarding the duration challenge puts people with mental illnesses at a disadvantage. To illustrate, only about 64,000 of those approved under the NDIS will have a mental illness yet the prevalence of severe mental illness in Australia is about 700,000 (Department of Health and Ageing, 2010).

There are positive aspects to the inclusion of mental illnesses in the NDIS. First, the NDIS recognizes that mental illnesses are a legitimate disability and that people with mental illnesses require more support. 
Second, there is an opportunity within the NDIS to provide early intervention support for people with mental illnesses to potentially reduce social and economic exclusion. Although, MHA reported that the NDIS has been designed to "exclude (or limit the number of) people with psychosocial disability from accessing NDIS funded early intervention supports" (MHA, 2017).

To improve some of these issues Allan Fels, the Australian National Mental Health Commission chairman, suggested designing a special gateway for people with mental illnesses applying for the NDIS (Gartrell, 2017). The Australian Government created a special Joint Standing Committee on the NDIS to look into the provision of services for people with mental illnesses (Parliament of Australia, 2017) which could include such a gateway. The Committee is set to report on its findings in late August 2017. The five challenges presented in my article provide a starting point for what issues policy-makers need to consider when designing a special gateway for people with mental illnesses.

For more information about the NDIS visit https://www.ndis.gov.au/ or read MHA's report "Response to the Productivity Commission National Disability Insurance Scheme (NDIS) Costs Position Paper."

\section{REFERENCES}

Andrews, K. (2014). Commonwealth doctors to assess new DSP claims [Press release]. Canberra: Retrieved Jan 8, 2014 from http://kevinandrews.com.au/latest-news/2014/12/12/commonwealth-doctors-assess-new-dsp-claims/

Australian Government. (2013). Senate Estimates-Hansard Transcripts. Retrieved Dec 5, 2012 from http://www.aph. gov.au/parliamentary_business/senate_estimates

Australian Government. (2015). Job capacity assessment (JCA). Guide to Social Security Law. Retrieved Aug 18, 2015 from http://guides.dss.gov.au/guide-social-security-law/1/1/j/10.

Bank of Canada. (2015). Year average of exchange rates. Retrieved May 5, 2016 from http://www.bankofcanada.ca/ stats/assets/pdf/nraa-2015-en.pdf

Barr, B., Taylor-Robinson, D., Stuckler, D., Loopstra, R., Reeves, A., \& Whitehead, M. (2015). 'First, do no harm': Are disability assessments associated with adverse trends in mental health? A longitudinal ecological study. Journal of Epidemiology and Community Health. doi:10.1136/jech-2015-206209

Bartram, M., \& Chodos, H. (2013). Changing Directions, Changing Lives: The Mental Health Strategy for Canada. Canadian Journal of Community Mental Health, 32(4). doi:10.7870/cjemh-2013-001

Baumberg, B., Warren, J., Garthwaite, K.,\& Bambra, C. (2015). Rethinking the work capability assessment. London, England: Demos.

Birks, M., \& Mills, J. (2010). Essentials of grounded theory. Thousand Oaks, CA: Sage .

Brucker, D. L. (2009). Social construction of disability and substance abuse within public disability benefit systems. International Journal of Drug Policy, 20(5), 418-23.

Bryant, A., \& Charmaz, K. (2007). The SAGE handbook of grounded theory. London, England: Sage.

Canadian Mental Health Association: Ontario. (2016). Improving the medical review process for ODSP clients. Toronto, ON: Canadian Mental Health Association, Ontario Office. Retrieved February 20, 2017 from http://ontario.cmha. ca/news/improving-the-medical-review-process-for-odsp-clients/\#.WLQf6tUrKot

Carney, T. (1991). Disability Support Pension: Towards workforce opportunities or social control? University of NSW Law Journal, 14(2), 220-246.

Charmaz, K. (2006). Constructing grounded theory: A practical guide through qualitative analysis. Thousand Oaks, CA: Sage.

Copes, T., \& Bisgould, L. (2010). Respondents' factum: Director, Ontario Disability Support Program and Tranchemontagne and Werbeski. Toronto, ON: Sudbury Community Legal Clinic and Legal Aid Ontario.

Corbin, J., \& Strauss, A. (2008). Basics of qualitative research: Techniques and procedures for developing grounded theory. Thousand Oaks, CA: Sage. 
Currie, S. R., Fiest, K., \& Guyn, L. (2013). Using community-level mental health surveillance data to examine the relationship of depression prevalence to social determinants of health and access to mental health services. Canadian Journal of Community Mental Health, 32(1), 43-57.

Deber, R. B. (2005) Slaves to economists? A Canadian's view of the Australian health care system. Australian Health Review, 29(4), 386-391.

Department of Health and Ageing (2010). National mental health report 2010: Summary of 15 years of reform in Australia's mental health services under the National Mental Health Strategy 1993-2008. Canberra: Commonwealth of Australia.

[DHS] Department of Human Services. (2016a). Disability Support Pension: Eligibility basics. Retrieved May 25, 2016 from http://www.humanservices.gov.au/customer/services/centrelink/disability-support-pension

DHS. (2016b). Medical evidence and assessment. Retrieved July 6, 2016 from http://www.humanservices.gov.au/ customer/enablers/medical-evidence-and-assessment

[DSS] Department of Social Services. (1991). Social Security Act, 1991. Canberra, ACT: Australian Department of Social Services.

DSS. (2012). Social Security (Tables for the assessment of work-related impairment for Disability Support Pension) Determination 2011. Canberra, ACT: Australian Department of Social Services.

DSS. (2013). Characteristics of Disability Support Pension recipients: June 2013. Canberra, ACT: Australian Department of Social Services. Retrieved July 6, 2016 from http://www.dss.gov.au/sites/default/files/documents/01_2014/ dsp_characteristics_report_2013_final.pdf

DSS. (2014). A new system for better employment and social outcomes: Interim report of the Reference Group on Welfare Reform to the Minister for Social Services. Canberra, ACT: Australian Department of Social Services. Retrieved July 6, 2016 from https://www.dss.gov.au/sites/default/files/documents/02_2015/dss001_14_final_ report_access_2.pdf

Dolowitz, D. P., \& Marsh, D. (2000). Learning from abroad: The role of policy transfer in contemporary policy-making. Governance, 13(1), 5-23.

Dunlop, M. (1983). Australia looks to Canada's Medicare. Canadian Medical Association Journal, 129(10), 1140.

Fryers, T., Melzer, D., \& Jenkins, R. (2003). Social inequalities and the common mental disorders. Social Psychiatry and Psychiatric Epidemiology, 38(5), 229-237.

Fryers, T., Melzer, D., Jenkins, R., \& Brugha, T. (2005). The distribution of the common mental disorders: Social inequalities in Europe. Clinical Practice and Epidemiology in Mental Health, 1(14). doi:10.1186/1745-0179-1-14

Gartrell, A. (2017) 'More people need to get in': Allan Fels calls for radical rethink of NDIS on mental illness. The Sydney Morning Herald 25 July 2017. Retrieved August 8, 2017 from: http:/www.smh.com.au/federal-politics/ political-news/more-people-need-to-get-in-allan-fels-calls-for-radical-rethink-of-ndis-on-mental-illness20170725-gxiaqs.html

Gray v. Director of the Ontario Disability Support Program. (2002). 59 O.R. (3d) 364 [Court of Appeal for Ontario]. Retrieved Sept 20, 2015 from http://www.canlii.org/en/on/onca/doc/2002/2002canliii7805/2002canlii7805. html?autocompleteStr=59\%20O.R.\%20(3d)\%20364\%20\&autocompletePos=1

Hales-Ricalis, C. (2010). Lessons to be learned: The decision of the Social Benefits Tribunal in Tranchemontagne v. Ontario (Director, Disability Support Program). Critical Disability Discourse, 2(2), 1-16.

Heim, C., \& Nemeroff, C. B. (2001). The role of childhood trauma in the neurobiology of mood and anxiety disorders: Preclinical and clinical studies. Biological Psychiatry, 49(12), 1023-1039.

Hurley, J., Vaithianathan, R., Crossley, T., \& Cobb-Clark, D. (2002). Parallel private health insurance in Australia: A cautionary tale and lessons for Canada. Canberra, ACT: Centre for Economic Policy Research.

Income Security Advocacy Centre. (2015). OW and ODSP rates and OCB amounts-2015. Toronto, ON: Income Security Advocacy Centre.

Judd, F. K., \& Humphreys, J. S. (2001). Mental health issues for rural and remote Australia. Australian Journal of Rural Health, 9(5), 254-258.

Karolinska Institutet. (2017) Läkarprogrammet—Hälsa I samhälle och miljö. Stockholm: Karolinska Institutet.

Kessler, R. C., \& Foster, C. L. (1995). Social consequences of psychiatric disorders, I: Educational attainment. American Journal of Psychiatry, 152(2), 1026-1032. 
Kieling, C., Baker-Henningham, H., Belfer, M., Conti, G., Ertem, I., Omigbodun, O., ... Rahman, A. (2011). Child and adolescent mental health worldwide: Evidence for action. The Lancet, 378(9801), 1515-1525.

Kohn, R., Saxena, S., Levav, I., \& Saraceno, B. (2004). The treatment gap in mental health care. Bulletin of the World Health Organisation, 82(11), 858-866.

Lankin, F., \& Sheikh, M. A. (2012). Brighter prospects: Transforming social assistance in Ontario. Ontario Commission for the Review of Social Assistance. Toronto, ON: Ontario Ministry of Community and Social Services.

Lightman, E., Vick, A., Herd, D., \& Mitchell, A. (2009). 'Not disabled enough': Episodic disabilities and the Ontario Disability Support Program. Disability Studies Quarterly, 29(3). doi:10.18061/dsq.v29i3.932

Madden, R., Glozier, N., Mpofu, E., \& Llewellyn, G. (2011). Eligibility, the ICF and the UN Convention: Australian perspectives. BMC Public Health, 11(Suppl 4), S6. doi:10.1186/1471-2458-11-S4-S6

Malbon, E., Carey, G., \& Dickinson, H. (2017). Accountability in Public Service Quasi-markets: The Case of the Australian National Disability Insurance Scheme. Australian Journal of Public Administration, 1-14. doi:10.1111/1467-8500.12246

Malterud, K. (2001). Qualitative research: Standards, challenges, and guidelines. The Lancet, 358(9280), $483-488$.

McAllister A, Hackett M. L., \& Leeder S. R. (2017). What evidence is available on disability income support design and mental illness? A review of Australia and Ontario. Public Health Policy \& Practice, 27(2):e2721715. doi:10.17061/phrp2721715

McGorry, P. D., \& Goldstone, S. (2011). Is this normal? Assessing mental health in young people. Australian Family Physician, 40(3), 94-97.

[MCSS] Ministry of Community and Social Assistance. (1997). Ontario Disability Support Program Act, 1997. Toronto, $\mathrm{ON}$ : Government of Ontario.

MCSS. (2011) Overview of the Ontario Disability Support Program (ODSP). Toronto, ON: Ontario Ministry of Community and Social Services.

MCSS. (2012). Applying for ODSP Income Support-Part Two. Retrieved July 6, 2016 from http:/www.mcss.gov. on.ca/en/mcss/programs/social/odsp/income_support/part_two.aspx.

MCSS. (2013). Taking Steps to Transform Social Assistance, [Press release]. Toronto: Ministry of Community and Social Services. Retrieved July 8, 2016 from http:/www.mcss.gov.on.ca/en/mcss/news/releases/2013/20130522.aspx.

MCSS. (2016a). Ontario Disability Support Program. Ontario social assistance: Monthly statistical report. Toronto, ON: Ontario Ministry of Community and Social Assistance. Retrieved March 21, 2016 from www.mcss.gov. on.ca/documents/en/mcss/social/reports/ODSP_EN_2016-01.pdf.

MCSS. (2016b). 2016-17 published plan. Toronto: Ministry of Community and Social Services. Retrieved February 20, 2017 from http://www.mcss.gov.on.ca/en/mcss/about/ppar/index.aspx

Mendelson, G. (2004). Survey of methods for the rating of psychiatric impairment in Australia. Journal of Law and Medicine, 11(4), 446-481.

Mental Health Australia. (2017). Response to the Productivity Commission National Disability Insurance Scheme (NDIS) Costs Position Paper. Canberra: Mental Health Australia. Retrieved August 10, 2017 from https://mhaustralia. $\mathrm{org} / \mathrm{sites} / \mathrm{default} / \mathrm{files} / \mathrm{docs} / \mathrm{mha}$ response to ndis_costs_position_paper.pdf

[MHCC] Mental Health Commission of Canada. (2012). Changing directions, changing lives: The mental health strategy for Canada. Calgary, AB: Mental Health Commission of Canada.

[MHCA \& NMHCCF] Mental Health Council of Australia, \& the National Mental Health Consumer and Carer Forum. (2014). Making the welfare system work for mental health consumers and carers: Submission to the Interim Report by the Reference Group on Welfare Reform. Canberra, ACT: Mental Health Council of Australia.

Meterko, M., Marfeo, E. E., McDonough, C. M., Jette, A. M., Ni, P., Bogusz, K., ... Chan, L. (2015). Work disability functional assessment battery: Feasibility and psychometric properties. Archives of Physical Medicine and Rehabilitation, 96(6), 1028-1035.

Morton, R. (2017, April 6) Mental health in NDIS a 'mistake', says Patrick McGorry. The Australian. Retrieved August 8, 2017 from http://www.theaustralian.com.au/national-affairs/health/mental-healthin-ndis-a-mistake-says-patrick-mcgorry/news-story/7ad228fc1067ff76f0a0c961a6dc1618

Moulding, R., Grenier, J., Blashki, G., Ritchie, P., Pirkis, J. \& Chomienne, M-H. (2009). Integrating psychologists into the Canadian health care system: The example of Australia. Canadian Journal of Public Health, 100(2), $145-147$. 
Mulvale, G., \& Bartram, M. (2015). No More "Us" and “Them": Integrating Recovery and Well-Being into a Conceptual Model for Mental Health Policy. Canadian Journal of Community Mental Health, 34(4), 1-37.

Mulvale, G., \& Bourgeault, I. L. (2007). Finding the right mix: How do contextual factors affect collaborative mental health care in Ontario? Canadian Public Policy, 33(S1), S49-S64.

Muntaner, C., Eaton, W., Miech, R., \& O’Campo, P. (2004). Socioeconomic position and major mental disorders. Epidemiologic Reviews, 26(1), 53-62.

O’Reilly, R., Bishop, J., Maddox, K., Hutchinson, L., Fisman, M., \& Takhar, J. (2007). Is telepsychiatry equivalent to face-to-face psychiatry? Results from a randomized controlled equivalence trial. Psychiatric Services, 58(6), 836-843.

[OECD] Organisation for Economic Co-operation and Development. (2012). Sick on the job? Myths and realities about mental health and work. Mental health and work. Paris: OECD Publication Services.

Parliament of Australia. (2017). The provision of services under the NDIS for people with psychosocial disabilities related to a mental health condition. Retrieved on August 8, 2017 from http://www.aph.gov.au/Parliamentary_Business/ Committees/Joint/National_Disability_Insurance_Scheme/MentalHealth

Penrod, J., Preston, D. B., Cain, R. E., \& Starks, M. T. (2003). A discussion of chain referral as a method of sampling hard-to-reach populations. Journal of Transcultural Nursing, 14(2), 100-107.

Prince, M., Patel, V., Saxena, S., Maj, M., Maselko, J., Phillips, M. R., \& Rahman, A. (2007). No health without mental health. The Lancet, 370(9590), 859-877.

Sbaraini, A., Carter, S., Evans, R., \& Blinkhorn, A. (2011). How to do a grounded theory study: A worked example of a study of dental practices. BMC Medical Research Methodology, 11. doi:10.1186/1471-2288-11-128

Stone, D. A. (1984), The disabled state. Philadelphia, PA: Temple University Press.

Tansey, O. (2007), Process tracing and elite interviewing: A case for non-probability sampling. PS: Political Science \& Politics, 40(4), 765-772.

Tempier, R., Meadows, G. N., Vasiliadis, H.-M., Mosier, K. E., Lesage, A., Stiller, A., ... Lepnurm, M. (2009). Mental disorders and mental health care in Canada and Australia: Comparative epidemiological findings. Social Psychiatry and Psychiatric Epidemiology, 44(1), 63-72.

Trainor, J., Pomeroy, E., \& Pape, B. (2004). A framework for support (3rd ed.). Toronto, ON: Canadian Mental Health Association, National Office. Retrieved March 6, 2018 from https://cmha.bc.ca/wp-content/uploads/2015/11/ Framework for_Support.pdf

Walker, S. P., Wachs, T. D., Grantham-McGregor, S., Black, M. M., Nelson, C. A., Huffman, S. L., ... Lozoff, B. (2011) Inequality in early childhood: Risk and protective factors for early child development. The Lancet, 378(9799), 1325-1338.

Whiteford, H. A., Buckingham, W. J., Harris, M. G., Burgess, P. M., Pirkis, J. E., Barendregt, J. J., \& Hall, W. D. (2014). Estimating treatment rates for mental disorders in Australia. Australian Health Review, 38(1), 80-85. 